\title{
SOLAR DRYING OF PINE LUMBER: VERIFICATION OF A MATHEMATICAL MODEL
}

\author{
Naoual Bekkioui ${ }^{1}$, Abdelillah Hakam ${ }^{1}$, André Zoulalian', \\ Abdessadek Sesbou ${ }^{3}$, Mohamed El Kortbi ${ }^{4}$
}

\begin{abstract}
This work presents verification of a mathematical model for drying of a wood stack in a greenhouse type solar dryer. A simplified heat and mass transfer numerical model has been developed with input parameters based on the actual metrological data of a Moroccan climate. For its validation, a comparative study is performed in this work; the present model is solved to simulate the solar drying of pine wood using experimental data of previous wood drying experiments. The average relative discrepancies between the model predicted and experimental data are 1,2\% for wood moisture content, $1 \%$ for drying air temperature and 5\% for the air relative humidity. The close agreement between the predicted and experimental results shows the ability of the model to reproduce experimental drying data for wood.
\end{abstract}

Keywords: Pine, solar dryer, modelling, moisture content, temperature

\section{INTRODUCTION}

In the past few decades, considerable work has been done on the development of new drying technologies. Many of these studies are on the use of solar dryers for wood drying. The results obtained from the previous studies claimed several advantages of solar wood drying technique (Taylor and Weir 1984, Chen and Helton 1989, Reuss et al. 1997, Haque and Langrish 2003). With the solar drying, the drying time is significantly shorter than open air drying, damage of the wood during drying could be avoided, drying to a very low equilibrium moisture content is possible for most locations, operating costs are low and less skill is required to operate than for conventional dryers since neither special control equipment nor fuel is necessary. For instance, a low cost solar heated experimental dryer was installed in Madrid to study the efficiency of solar drying of sawn lumber in Spain, as compared with normal air drying (Alvarez Noves and Fernández-Golfín Seco, 1990). The results have proven that the drying time was much shorter than for open air drying (up to 3.5 times faster than air drying). The quality of dried wood was mostly better compared to normal air drying and also to conventional dryer drying. Another semi-greenhouse solar dryer was designed and constructed in Egypt to dry Casuarina (Helwa et al. 2004). A comparison was made between experimental results of solar wood drying and traditional air-drying. The results from the project also confirmed the advantages of solar wood drying as mentioned above. With the same drying time, the boards were dried inside solar dryer to moisture content lower than for air drying.

In Morocco, several imported species of wood including pine are used to make furniture. Other local species, e.g. thuya, are highly desirable for their attractive qualities for decoration and joinery.

\footnotetext{
This paper was originally presented at the 2010 IAWS/ESTB7 meeting, Rabat-Morocco, March 2010, and has been updated ${ }^{1}$ Laboratoire des Sciences et Technologie du Bois, Faculté des Sciences, 4 Avenue Ibn Battouta, BP 1014 R abat, Maroc

${ }^{2}$ LERMAB-Université de Nancy 1, BP 239-54560 Vandoeuvre les Nancy, France

${ }^{3}$ Ecole Nationale Forestière d'Ingénieurs (ENFI), BP 511-11000 Salé, Maroc

${ }^{4}$ Centre Technique des Industries du Bois et de l'Ameublement (CTIBA), Casablanca, Maroc

Corresponding author: bekkioui_naoual@yahoo.fr

Received: 07.06.2010 Accepted: 30.11.2010.
} 
Currently in many cases, the wood is dried in the open air under the sun, which has limitations like insect infestation or the product being over-dried as there is no control of the temperature and the humidity, resulting sometimes in complete damage. To obtain a high quality product and to reduce the drying time, controlled drying is required. In this case, wood is dried in conventional dryers whose energy inputs are generally fossil fuels (gas combustion or liquid). However, the annually dried volume of wood from the controlled kiln drying is limited. In Morocco, only $8000 \mathrm{~m}^{3}$ of wood used in the sawing and the joinery is dried with controlled drying kiln in 13 firms (Benjelloun 1996). The high operating costs are the main reason that prevents firms from using controlled kiln drying. In this context and to develop wood drying in Morocco, some experimental studies have shown that the solar wood drying will potentially play an important role in the future wood drying (Khadouri 1986, Youssefi 1997, El kannafi 2002). All these studies have supported the use of greenhouse type solar wood dryers because they have low cost, easy operation and simple construction with locally available materials.

The optimization of the operation of solar wood dryers requires, however, fundamental standing of the drying process and influence of drying conditions on the drying time and drying quality. The understanding of the drying mechanisms is very useful to the interpretation of the drying process. Indeed, studying solar wood dryers through a combination of mathematical modeling and experiments permits the improvement of the energy efficiency of solar dryers and to quantify the variability in solar energy inputs and wood properties. A modeling and simulation of a wood solar dryer in a Moroccan climate have been proposed by Bentayeb et al. (2008). A fairly simple model that considers an average temperature of the dryer (air, wood and walls) gave reasonable results. The drying time was found to be closely linked to glass partitions and wood thickness, however, the type of ventilation was found to have no effect on the drying time. In the study of Bentayeb et al. (2008), no comparison between simulated results and experimental measurements was presented. Considering this first approach insufficient for modeling an actual dryer, a second approach that considers for each element of the dryer and practical drying temperature has been recently developed by Bekkioui et al. (2009). A comparative study has been established in the same work to validate the mathematical model by applying the model to the data of two drying trials performed for two wood species in two different Moroccan climates (Casablanca: $33^{\circ} 32^{\prime} \mathrm{N}, 7^{\circ} 41^{\prime} \mathrm{W}$ and Essaouira: $\left.31^{\circ} 31^{\prime} \mathrm{N}, 9^{\circ} 47^{\prime} \mathrm{W}\right)$. However, the comparison was only conducted for model computed and experimentally measured moisture content. In the present study, the model developed by Bekkioui et al. (2009) is solved to predict dryer humidity and temperatures (air and walls) as well as wood temperature and moisture contents which are verified with the experimental results conducted in Casablanca on pine wood.

\section{MATERIALS AND METHODS}

\section{Experimental Protocol}

To experimentally verify the model developed, this model was executed within the simulation program with practical drying conditions from wood drying experiment conducted at Public laboratory of Studies and Tests (LPEE) of Casablanca (Youssefi 1997). This experiment was conducted on pine wood (Pinus pinaster) whose density $\rho_{0}=450 \mathrm{~kg} / \mathrm{m}^{3}$. 


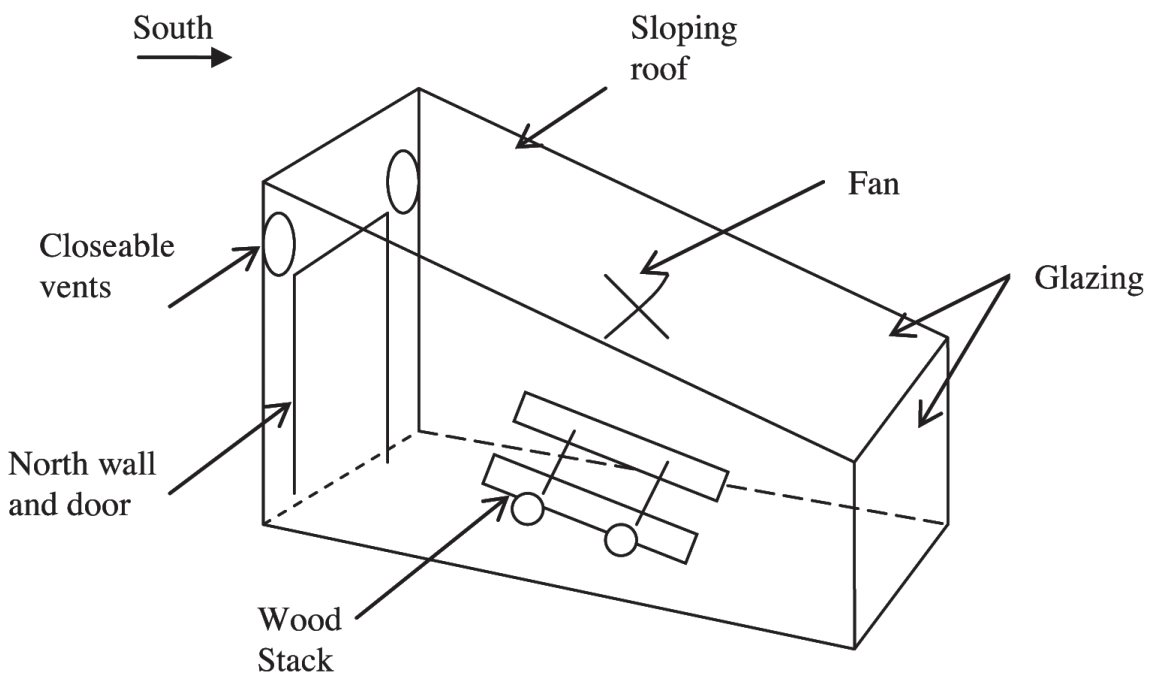

Figure1. Schematic representation of the solar wood dryer

In the experiment, $1 \mathrm{~m}^{3}$ of pine ( $27 \mathrm{~mm}$ thick boards) was dried in a greenhouse type solar dryer with a drying air velocity equal to $1 \mathrm{~m} / \mathrm{s}$ and an exchange surface wood-air of $44 \mathrm{~m}^{2}$. The dryer (Figure 1 ) has dimensions of $2.5 \mathrm{~m} \mathrm{x} 1.8 \mathrm{~m} \mathrm{x}$ (1.45 m south, 2, $25 \mathrm{~m}$ north). The sloping roof and three of the walls (east, west and south) are made of glass window panels mounted on a light wooden frame. The roof faces south at a slop of 25 degrees, an inclination that allows better optimization of solar radiation inputs while minimizing the inside volume unusable for stacking wood. The north insulated wall incorporates a door to admit the wood load. Air is circulated within the dryer by an electric fan placed above the wood stack. Humid air is manually removed from the dryer from 10 am to $4 \mathrm{pm}$ by closeable vents in the rear wall. For good insulation, the floor and the north wall are made of two layers of cork $(0.033 \mathrm{~m})$ and polystyrene $(0.002 \mathrm{~m})$ lain between a layer of concrete $(0.12 \mathrm{~m})$ and a layer of cement $(0.045 \mathrm{~m})$.

Table 1 represents the characteristics related to the drying cycle performed in the described dryer.

Table 1. Characteristics of the drying cycle performed in Casablanca

\begin{tabular}{|c|c|c|c|c|c|c|c|}
\hline Experiment & $\begin{array}{c}\text { Wood } \\
\text { species }\end{array}$ & $\begin{array}{c}\text { Wood } \\
\text { thickness } \\
(\mathrm{mm})\end{array}$ & $\begin{array}{c}\text { Wood } \\
\text { density } \\
\left(\mathrm{kg} . \mathrm{m}^{-3}\right)\end{array}$ & $\begin{array}{c}\text { Wood } \\
\text { volume } \\
\left(\mathrm{m}^{3}\right)\end{array}$ & $\begin{array}{c}\text { Fill } \\
\text { factor } \\
\left(V_{b} / V\right)\end{array}$ & $S_{b}\left(\mathrm{~m}^{2}\right)$ & $\begin{array}{c}\text { Air } \\
\text { velocity } \\
\left(\mathrm{m} . \mathrm{s}^{-1}\right)\end{array}$ \\
\hline $\begin{array}{c}\text { Casablanca } \\
\text { (LPEE) }\end{array}$ & Pine & 27 & 450 & 1 & 0.14 & 44 & 1 \\
\hline
\end{tabular}

The climatic data and meteorological conditions used in the simulation program were provided to us by the Laboratory of Solar Energy of Mohammed V- Agdal University, Rabat. These data consist of the direct solar radiation on a plane perpendicular to the solar rays, the total solar radiation on a horizontal plane, ambient temperature, relative humidity and wind speed. They have been measured and recorded every six minutes but the data used was the average values over every hour. According to the data available and by applying relationships that give the total intensity of solar radiation on a sloped plane, we have calculated the solar energy received by the north wall and by the glazed walls of the dryer, namely, the sloped roof, the vertical south wall, the east wall and the west wall. 
The total radiation received by the glazed walls of the dryer in one day is shown in figure 2 . All curves have a similar cyclical pattern. The sloped roof receives the most important solar radiation, which increases progressively since the beginning of the day to reach its maximum value of $1200 \mathrm{~W} / \mathrm{m}^{2}$ at noon when the sun's rays become perpendicular to this face. In the afternoon, solar radiation decreases to become null around $7 \mathrm{pm}$.

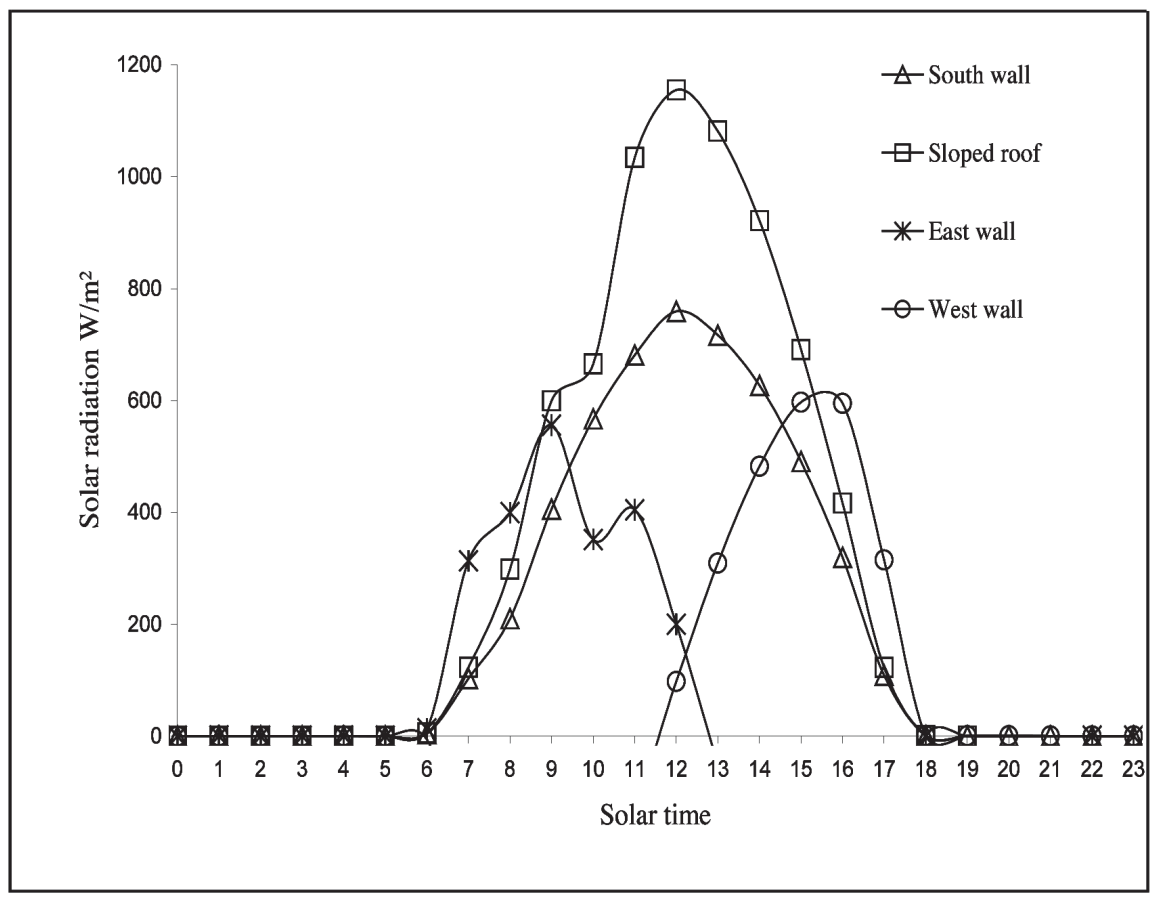

Figure 2. Hourly total solar radiation received by the glazed walls of the dryer

\section{Theoretical Approach}

Table 2. summarizes the considerations which the model equations are based on, however, the detailed equations can be found in Bekkioui et al. (2009)

Table 2. The model equations description

\begin{tabular}{|l|l|}
\hline \multicolumn{1}{|c|}{ Mass balances } & \multicolumn{1}{|c|}{ Energy Balances } \\
\hline Mass balance of water in the solid phase & Energy balance of glazing \\
Global mass balance of water in the gas phase & Energy balance of the north wall balance of the wood stack \\
& Energy balance of the gas phase \\
\hline
\end{tabular}

Except for the mass balance of water in the solid phase (wood), we use in this study two approaches to evaluate the mass transfer coefficient. While solving the model equations, we will use each approach independently and compare the results. 


\section{First Approach}

Since solar drying is slow, previous studies (Chrusciel et al. 1999 and Ananias et al. 2009) have shown that even above the fiber saturation point, the transfer of water within the wood can be expressed as:

$$
M_{0} \frac{d X}{d t}=-K_{e} S_{b}\left(X-X^{*}\right)
$$

The global mass transfer coefficient Ke may be expressed as a function of the partial mass transfer coefficient in the solid phase and the partial mass transfer coefficient in the gas phase. For low temperature convective drying conditions, Chrusciel et al. (1999) have developed an empirical correlation that takes into account the main operating parameters characterizing the wood and air during a drying cycle ( wood thickness, air velocity, air temperature and air humidity):

$$
\begin{aligned}
& \frac{1}{K_{e}}=a_{0} \cdot \exp \left(\frac{c_{0}}{T_{a}}\right) \cdot e+b_{0} \cdot \exp \left(\frac{c_{0}}{T_{a}}\right) \cdot v^{-p} \cdot \exp \left(-\frac{z}{X_{F S P}-X^{*}}\right) \\
& a_{0}=0,2265 ; \quad b_{0}=268,9 ; \quad c_{0}=2543,6 \quad p=2,7158 ; \quad \mathrm{z}=1-\frac{H R}{100}
\end{aligned}
$$

\section{Second Approach}

Taylor and Weir (1984) have suggested that the rate of water movement in wood might be described by an equation of the form:

$$
M_{0} \frac{d X}{d t}=-K \rho_{0} S\left(X-X^{*}\right)
$$

Insofar as $\mathrm{M}_{0}=\rho_{0} \mathrm{~S} e$, the equation (3) can be written:

$$
\frac{d X}{d t}=-\frac{K}{e}\left(X-X^{*}\right)
$$

The moisture movement coefficient $\mathrm{K}$ is a property primarily of wood. It depends on temperature and wood species. It is given by the following relation:

$$
K\left(\rho_{0}, T_{a}\right)=K_{0 a} \frac{W_{\text {sat }}\left(T_{a}\right)}{W_{\text {sat }}\left(T_{0 a}\right)} \frac{\rho_{0 a}}{\rho_{0}}
$$

Where $\mathrm{K}_{0 \mathrm{a}}=3,88.10^{-8} \mathrm{~m} \cdot \mathrm{s}^{-1}$ is the value for mahogany (Swietenia macrophylla) of basic density $\rho_{0 a}$ $=440 \mathrm{~kg} \cdot \mathrm{m}^{-3}$ at temperature $\mathrm{T}_{0 \mathrm{a}}=30^{\circ} \mathrm{C}$, and $\rho_{0}$ is the basic density of wood in question. 


\section{RESULTS AND DISCUSSION}

We have used independently Equation (1) or Equation (4) for the mass balance of water in the wood stack and compared the predicted wood moisture content results obtained using each equation. The solar drying model was solved numerically using a fourth order Runge Kutta method. All computations were done using a Turbo Pascal Program. The calculations were proceeded forward in steps of $\Delta \mathrm{t}=1$ minute, stored and recorded every hour (Bekkioui et al. 2009). Table 3 represents drying air and wood data used for the simulated process.

Table 3. Drying air and wood data for the simulated process

\begin{tabular}{|c|c|}
\hline \multicolumn{2}{|c|}{ Drying air } \\
\hline$v$ & $1 \mathrm{~m} / \mathrm{s}$ \\
\hline$\rho_{\mathrm{g}}$ & $1,41 \mathrm{~kg} \cdot \mathrm{m}^{-3}$ \\
\hline vent section & $0.02 \mathrm{~m} \times 0.02 \mathrm{~m}$ \\
\hline$G$ & 0.05 kg.s- ${ }^{1}$ \\
\hline$m_{a}$ & $12,7 \mathrm{~kg}$ \\
\hline \multicolumn{2}{|c|}{ Wood } \\
\hline$X_{0}$ & $0.35 \mathrm{~kg} / \mathrm{kg}$ \\
\hline$\rho_{0}$ & $450 \mathrm{~kg} \cdot \mathrm{m}^{-3}$ \\
\hline$V_{b}$ & $1 \mathrm{~m}^{3}$ \\
\hline$M_{0}$ & $334 \mathrm{~kg}$ \\
\hline
\end{tabular}

\section{Predicted Pine Moisture Content}

Fig.3 illustrates the predicted moisture contents of pine wood (expressed in percent) during drying. It is noticed that the use of the global mass transfer coefficient Ke evaluated by the Equation (2) or the moisture movement coefficient K evaluated by the Equation (5) for the mass balance of water in the wood has no significant difference on the drying curve. Further simulation results also show that the predicted results for other parameters are not significantly affected by the use of Ke or K in the model. 


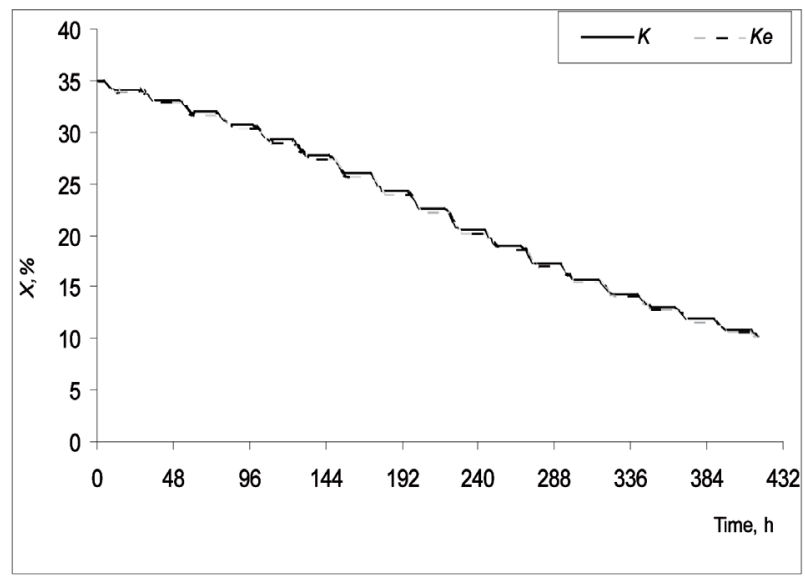

Figure 3. The predicted moisture content of pine

It is shown from the same figure that a period of 416 hours is necessary to dry pine wood from $35 \%$ to $10 \%$. The initial drying time 0 corresponds to 6 a.m., local time in Casablanca.

\section{Model Validation}

The validation of the present model is based on comparisons of the predicted and the measured wood moisture contents, drying air temperatures and relative humidities.

\section{a) Moisture Content Comparison}

Fig.4 illustrates the comparison between the experimental results and theoretical results of the moisture content of pine wood. On the same figure is represented the equilibrium moisture content $\left(X^{*}\right)$ calculated by the simulation program.

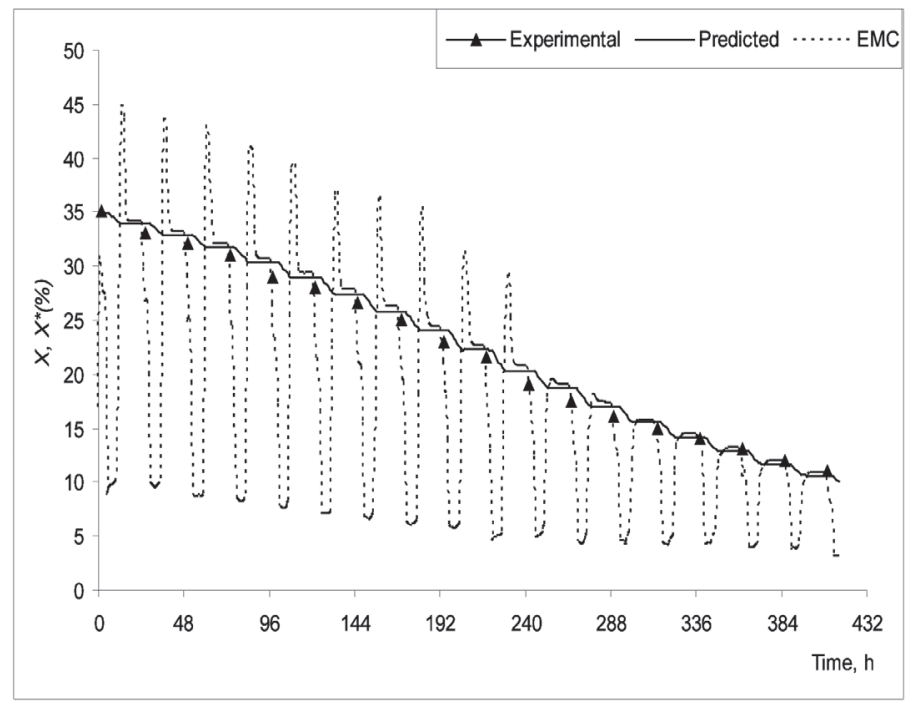

Figure 4. Comparison between previous experimental results and theoretical results of wood moisture content 
We can conclude from this figure that the experimental and theoretical results of wood moisture content have similar trends. Also, the theoretical curve shows that pine wood exhibits fast drying during the day time when $X^{*}$ is low, followed by humidification of wood at night, when the equilibrium moisture content is greater than the moisture content of wood.

To confirm and quantify the validity of the modelling, we have evaluated the average relative error of the predicted results compared with the measured ones during the whole drying time. Then, if $Y$ is the parameter to compare, the average relative error $E_{Y}$ is given by the following:

$$
E_{Y}=\frac{1}{N} \sum_{1}^{N}\left[\frac{\left|Y_{m e}-Y_{p r}\right|}{\frac{Y_{m e}+Y_{p r}}{2}}\right]
$$

Where:

$Y_{m e}$ is the measured value of $Y$

$Y_{p r}$ is the predicted value of $Y$

$N$ is the number of points (time) at which the comparison is established.

For wood moisture content, the mean relative error of the theoretical results compared with the experimental ones has been evaluated using daily values, since the hourly experimental information was not available to us. Indeed, only the daily experimental values of moisture content exist. Then, for $N$ equal to 17 (days of drying), the average relative error for wood moisture content is:

$E_{X}=1,2 \%$

$E_{X}$ is low, which confirms the close agreement between the actual and predicted moisture contents of pine wood during drying.

\section{b) Air Temperature Comparison}

The comparison between the experimental results and theoretical results of drying air temperature is shown in Figure 5. The agreement between the predicted and measured temperatures of the internal air is reasonable; both curves have a similar cyclical pattern.

Applying Equation (6), the average relative error of the theoretical results of drying air temperature compared with the previous experimental ones is:

$$
E_{T a}=1 \%
$$

With $N$ is equal to 416 hours in this case as $N$ represents the hours of drying.

The same as for the wood moisture contents, the average relative error of air temperature is low and shows the close agreement between the actual and predicted air temperatures during drying. 


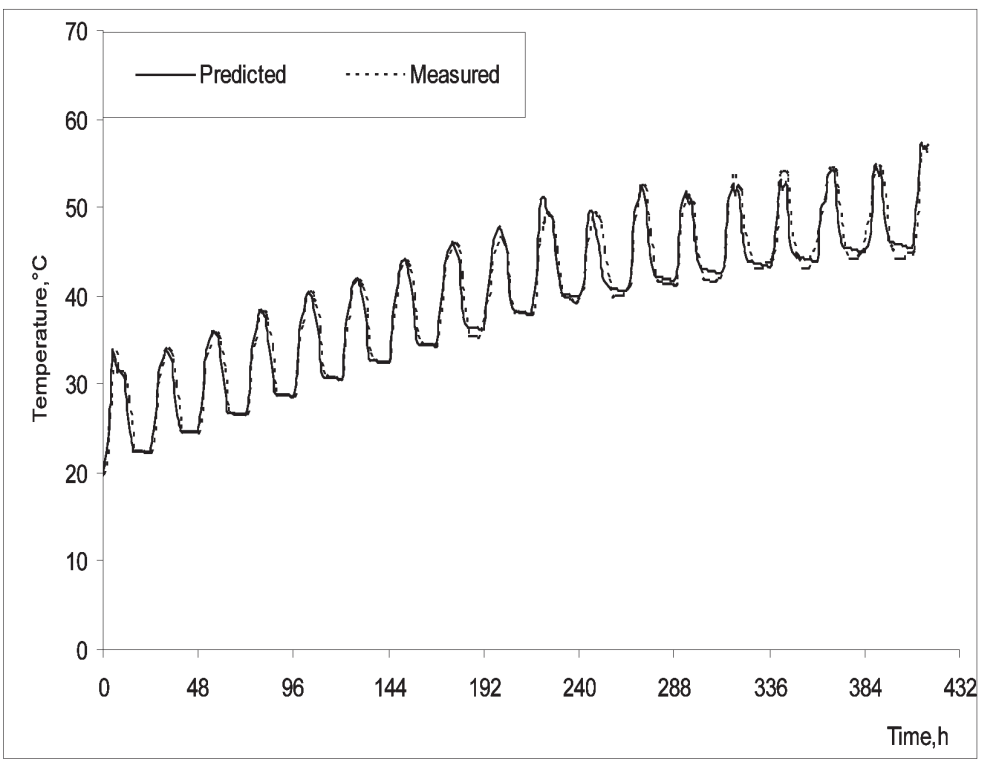

Figure 5. Comparison between previous experimental results and theoretical results of drying air temperature

\section{c) Relative Humidity Comparison}

Figure 6 illustrates the comparison between the experimental results and the theoretical results of drying air relative humidity. The agreement between the predicted and measured relative humidities of the internal air is also close although the discrepancy seems greater than that in Figure 4 and Figure 5.Also, we may conclude from Figure 5 and Figure 6 that, inside the dryer, the air temperatures and the air relative humidities vary in opposite ways. Indeed, the increase of air temperature at the beginning of the day leads to a decrease of the air relative humidity, which reaches its minimum when the temperature is at its maximum value. In the afternoon, when solar radiation diminishes and the air temperature decreases, this allows the relative humidity to increase progressively and reach its maximum value.

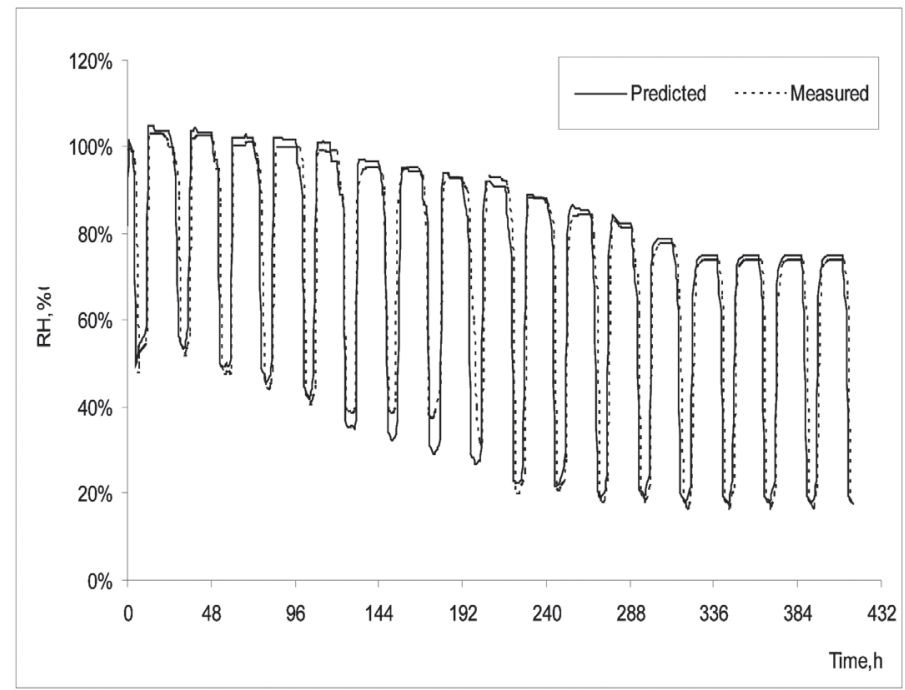

Figure 6. Comparison between previous experimental results and theoretical results of drying air relative humidity 
Applying equation (6), the average relative error of the theoretical results of drying air relative humidity compared with the previous experimental ones ( $N$ equal to 416 hours) is:

$$
E_{R H}=5 \%
$$

For the air relative humidity, the average relative error $E_{R H}$ is also low and shows reasonable agreement between the actual and predicted air relative humidities during drying. On the other hand, $E_{R H}$ is greater than the average relative errors of wood moisture content and air temperature. This difference is probably due to the measured relative humidities; in fact, they have been taken directly from the thermo hygrograph, so they are not very accurate $( \pm 10 \%)$.

\section{CONCLUSION}

A mathematical model for wood drying process developed on the basis of heat and mass transfer within the wood and the drying air is used to describe theoretically the pine solar drying process. The model used is mathematically simple, but it permits to predict the main key points of solar wood dryers (drying time, wood moisture content, air temperature and relative humidity). A period of almost 17 days is necessary to dry pine wood from $35 \%$ to $10 \%$. The theoretical investigation of pine drying process and its comparison with experimental work showed close agreement between the predicted and the measured results. The average relative errors of the theoretical results compared with the experimental ones are equal to or less than $5 \%$, which confirms the good accuracy of the modelling. The close agreement shows that the developed model is capable of describing the thermal and moisture content behavior of a wood solar dryer. It is concluded that the present model could be applied to all the greenhouse type of solar dryers that have a design similar to the dryer studied. So, the model could be an effective tool for solar drying technique. 


\section{REFERENCES}

Alvarez Noves, H.; Fernández-Golfín Seco, J.I. 1990. Solar drying of sawn lumber in Spain. European Journal of Wood and Wood Products 48(5): 173-178.

Ananias, R.A.; Mougel, E.; Zoulalian, A. 2009. Introducing an overall mass transfer coefficient for predicting of drying curves at low-temperature drying rates. Wood Sci. Technol 43: 43-56.

Bekkioui, N.; Zoulalian, A.; Hakam, A.; Bentayeb, F.; Sesbou, A. 2009. Modelling of a solar wood dryer with glazed walls. Maderas. Ciencia y tecnología 11(3): 191-205.

Benjelloun, K. 1996. Le séchage du bois au Maroc. Rapport interne, LPEE

Bentayeb, F.; Bekkioui, N.; Zeghmati, B. 2008. Modelling and simulation of a wood solar dryer in a Moroccan climate. Renewable Energy 33: 501-506.

Chen, P.Y.S.; Helton, C.E. 1989. Design and evaluation of a low-cost solar kiln. Forest Products Journal 39 (1): 19-22.

Chrusciel, L.; Mougel, E.; Zoulalian, A.; Meunier, T. 1999. Characterisation of water transfer in a low temperature convective wood drier: influence of the operating parameters on the mass transfer coefficient. Holz als Roh- und Werkstoff 57: 439-445.

El kannafi, A. 2002. Etude de la faisabilité du séchage solaire du bois de Thuya dans la ville d'Essaouira. Mémoire de 3ème cycle, Ecole Nationale Forestière d'Ingénieurs de Salé.

Haque, M.N.; Langrish, T.A.G. 2003. The Assessment of the Performance of a Solar Kiln and Its Model Validation for Drying Timber. $3^{\text {rd }}$ Asia-Pacific Drying Conference, Asian Institute of Technology. ADC'03: 143-152.

Helwa, N. H.; Khater, H. A.; Enayet, M. N.; Hashish, M.I. 2004. Experimental Evaluation of Solar Kiln for Drying Wood. Drying Technology 22(4): 703-717.

Khadouri, A. 1986. Le séchage du bois au Maroc, conception d'un séchoir solaire. Mémoire de 3éme cycle agronomie, IVA Hassan II de Rabat.

Reuss, M.; Benkert, S.T.; Aeberhand, A.; Martina, P.; Raush, G.; Rentzell, B.V.; Sogar, N. 1997. Modelling and experimental investigation of a pilot plant for solar wood drying. Solar Energy 59(4-6): 259-270.

Taylor, K.J.; Weir, A.D. 1984. Simulation of solar timber dryer. Solar Energy 34 (3): 249-255.

Youssefi, M. 1997. Le séchage du bois au Maroc, construction et expérimentation d'un séchoir solaire pilote. Mémoire de 3ème cycle. IVA Hassan II, Rabat. 


\section{NOMENCLATURE}

$G$ : mass flow rate of dry air, kg. $\mathrm{s}^{-1}$

$H R$ : relative humidity, $\%$

$K$ : moisture movement coefficient, $\mathrm{m} \cdot \mathrm{s}^{-1}$

$K_{e}$ : global mass transfer coefficient wood water - gas water, $\mathrm{kg} \cdot \mathrm{m}^{-2} \cdot \mathrm{s}^{-1}$

$M_{0}$ : oven dry mass of the wood, $\mathrm{kg}$

$m_{a}:$ mass of dry air, $\mathrm{kg}$

$S$ : lateral surface of the wood pieces in the dryer, $\mathrm{m}^{2}$

$S_{b}$ : exchange surface between the wood stack and the drying air, $\mathrm{m}^{2}$

$T_{a}:$ air temperature, $\mathrm{K}$

$V_{b}:$ volume of the wood in the dryer, $\mathrm{m}^{3}$

$W_{\text {sat }}:$ saturated humidity of drying air, $\mathrm{kg} \cdot \mathrm{kg}^{-1}$

$X:$ moisture content of wood, $\mathrm{kg} \cdot \mathrm{kg}^{-1}$

$X_{0}$ : initial moisture content of wood, $\mathrm{kg}_{\mathrm{kg}} \mathrm{kg}^{-1}$

$X^{*}$ : equilibrium moisture content of wood (EMC), $\mathrm{kg}_{\mathrm{kg}} \mathrm{kg}^{-1}$

$X_{P S F}:$ moisture content of wood at Fiber Saturation Point, kg.kg-1

$e$ : wood thickness, $\mathrm{m}$

$v$ : air velocity, $\mathrm{m} \cdot \mathrm{s}^{-1}$

$\rho_{0}$ : basic density of wood, kg.m $\mathrm{m}^{-3}$

$\rho_{g}:$ air density 